\title{
Educação ambiental nas escolas da rede municipal de ensino de Campo Grande, Mato Grosso do Sul
}

\author{
Environmental education in municipal schools \\ in the city of Campo Grande, Mato Grosso do Sul
}

Datrícia Pato dos Santos ${ }^{1}$

Gilberto Luiz Alves ${ }^{1}$ 1Universidade Anhanguera-Uniderp, Programa de Pós-graduação em Meio Ambiente e Desenvolvimento
Regional, Campo Grande, MS, Brasil. Autora correspondente: ppscgms@gmail.com

Resumo: Este artigo tem como objeto a educação ambiental, tal como vem se desenvolvendo na Rede Municipal de Ensino (Reme) de Campo Grande, estado de Mato Grosso do Sul, com o propósito de apreender a sistematização da educação ambiental na escola pública contemporânea. Temos como questão norteadora a forma pela qual o trabalho didático se realiza no âmbito da educação ambiental escolar, enquanto forma concreta de trabalho na escola. O procedimento de pesquisa consistiu na análise de manuais didáticos do ensino fundamental das áreas de Geografia e Ciências, e observações sistemáticas nas reuniões de formação continuada de professores. Os dados foram analisados à luz do referencial teórico-metodológico ciência da história. Foi constatado que a educação ambiental, da mesma forma que a educação em geral, assumiu um caráter livresco e verbalista que a afasta do rigor científico e das experiências vivas constituídas pelas relações entre o homem e o ambiente.

Palavras-chave: Educação ambiental; Escola pública; Trabalho didático; Orientação didática.

Abstract: The object in this article is environmental education, as it has been developed in the Municipal Education Network (Reme) of Campo Grande, Mato Grosso do Sul. The objective is to understand the systematization of environmental education in the contemporary public school. The guiding question is the way in which didactic work is carried out within the scope of environmental education at school. It is based on the didactic work category as a concrete form of school work. The research procedure consisted of analysis of didactic manuals in the areas of Geography and Science in elementary education, and systematic observations in meetings for teachers' continuing education. The data were analyzed in the light of the theoreticalmethodological framework of science of history. It was found that environmental education, like education in general, took on a bookish and verbal character that distances itself from scientific rigor and from the living experiences constituted by the relations between men and the environment.

Keywords: Environmental education; Public school; Didactic work; Didactic guidance.

Recebido em: 02/08/2020

Aprovado em: 22/02/2021 


\section{Introdução}

O presente estudo está assentado no pressuposto de que a historicidade do conhecimento humano resulta das relações que os homens estabelecem com a natureza e com os outros homens, ambas mediadas pelo trabalho. Está fundamentado na categoria trabalho didático enquanto forma concreta de como o trabalho se realiza na escola. Tem por objeto a educação ambiental, tal como vem sendo desenvolvida na Rede Municipal de Ensino (Reme) de Campo Grande, estado de Mato Grosso do Sul. Apresenta como objetivo apreender a sistematização da educação ambiental na escola pública contemporânea.

A questão norteadora quanto à abordagem leva em conta a forma pela qual o trabalho didático se realiza no âmbito da educação ambiental escolar. Tem-se como hipótese que a educação ambiental tem sido incapaz de contribuir para que os estudantes entendam as contradições que, sob o capitalismo, geram ameaças ao ambiente ou, sequer, participem do debate ambiental.

Ao estabelecer uma relação estritamente utilitarista com o ambiente, o capital intensificou a exploração dos recursos naturais. Surgiram como decorrência os problemas ambientais. Sua escala mundial passou a exigir soluções globais da sociedade.

Resumidamente, desde as origens, a sociedade capitalista se pautou em relações de produção que envolvem os proprietários dos meios de produção de um lado, e os detentores de força de trabalho, de outro. No modo de produção capitalista observase a transformação da natureza e do trabalho em mercadoria. É a relação de produção que define a interação entre homem e natureza, e também prioriza o valor de troca em detrimento do valor de uso. (ALVES, 2014).

A finalidade buscada sempre foi a produção de excedentes e o estímulo ao consumo. Por ignorar o caráter finito dos recursos naturais, isso veio a causar impactos no ambiente e na própria vida do homem.

[...] Ainda no dia de ontem, a humanidade vivia tomada pelo medo de pragas e pestes, como a da varíola, a da cólera, ou a da bubônica, que outrora dizimavam nações por onde passavam. Agora, a nossa principal preocupação não são mais os organismos provocadores de doenças, que em outros tempos se faziam onipresentes. Os serviços de ordem sanitária, as melhores condições de vida, juntamente com o uso de novos remédios, nos deram alto controle sobre as enfermidades infecciosas. Hoje, preocupamo-nos com uma espécie diferente de risco, que perpassa pelo nosso meio ambiente: um risco que nós mesmos introduzimos no nosso mundo, na medida em que o nosso moderno estilo de vida veio evoluindo e se formando. (CARSON, 1962, p. 195).

Entendida como uma das formas de responder aos desequilíbrios ambientais, a educação ambiental passou a ser definida como "[...] o conjunto de processos por meio dos quais o homem e a coletividade constroem valores sociais, conhecimentos, habilidades, atitudes e competências voltadas para a conservação do meio ambiente". (BRASIL, 1999).

A educação ambiental foi institucionalizada no Brasil pela Lei $n^{\circ} 6.938 / 1981$ (BRASIL, 1981), que dispõe sobre a Política Nacional do Meio ambiente (PNMA). A partir 
de 1987, segundo resolução do Conselho Nacional de Educação (BRASIL, 1987), ela passaria a incluir, de "modo interdisciplinar", os currículos de todos os níveis de ensino.

A importância ambiental ganhou ainda mais destaque no ano de 1992, quando ocorreu a Conferência das Nações Unidas sobre Meio Ambiente e Desenvolvimento (RIO-92 ou ECO-92). [...] Nesse mesmo ano, também foi elaborada a Agenda 21, sendo a UNESCO e o Ministério do Meio Ambiente os órgãos responsáveis pelo cumprimento dos compromissos assumidos, assim como pela execução do Programa Nacional de Educação Ambiental. (TALAMONI et al., 2018, p. 61).

Com a promulgação da nova Constituição Federal (BRASIL, 1988), foi consolidada a obrigatoriedade da educação ambiental em todos os níveis de ensino. Ela seria instrumento importante para assegurar a efetividade do direito de todos ao meio ambiente ecologicamente equilibrado.

A Lei de Diretrizes e Bases da Educação (LDB) (BRASIL, 1996) apresentou poucas menções à educação ambiental. Mas frisou a necessidade de os currículos abrangerem o conhecimento do mundo físico e natural, e da realidade social e política, especialmente do Brasil, que, sem dúvida, envolve implicações para a educação ambiental.

A Política Nacional de Educação Ambiental (PNEA), criada em 1999, reforçou o direito de todos à educação ambiental, indicando seus princípios e objetivos (BRASIL, 1999). Já o Plano Nacional de Educação (PNE), datado de 2014, incluiu a educação ambiental como tema transversal e observou que ela deveria ser implementada no ensino fundamental e no ensino médio (BRASIL, 2014).

Enquanto documentos norteadores da educação básica, os Parâmetros Curriculares Nacionais (BRASIL, 1997), as Diretrizes Curriculares Nacionais da Educação Básica (BRASIL, 2013), e a Base Nacional Comum Curricular (BRASIL, 2017) reforçaram o caráter interdisciplinar da educação ambiental no tratamento das questões de sustentabilidade e da relação homem-natureza.

Este artigo busca um caminho que permita compreender a educação de forma a reforçar a importância do conhecimento e da ciência. Por oposição aos estudos que reduzem as análises da escola ao campo ideológico, o foco é a materialidade da instituição. Há autores que defendem ser o fim último da educação escolar fornecer aos indivíduos os instrumentos necessários para se apoderarem dos códigos de uma sociedade em constante mutação, baseada na informação e no conhecimento (DELORS, 1999). Sob esse aspecto, não é possível atribuir onipotência à educação. Não basta o acesso para garantir aos usuários a compreensão das complexas relações sociais que permeiam o mundo dos homens.

Atualmente, a escola se legitima pela transmissão de conhecimentos. No entanto, ao reforçar o ensino por meio de conteúdos selecionados, cuja intencionalidade não está explícita, a instituição termina por reproduzir as desigualdades sociais e ampliar o atendimento às necessidades do capital. Por isso, a compreensão da educação, na atualidade, precisa abarcar a percepção de suas dimensões social, econômica e cultural. Esse enfoque é chave para enfrentar os desafios gerados pela constante evolução científica e tecnológica e para possibilitar questionamentos e reflexões acerca de velhos paradigmas estabelecidos, postos como verdades absolutas.

Isso tem repercussões, necessariamente, no âmbito da educação ambiental escolar, que não consegue se desvencilhar dos condicionamentos impostos ao trabalho 
didático associado à especialização do saber e, como decorrência, à fragmentação dos conhecimentos disciplinares.

\section{Material e métodos}

O referencial teórico foi estabelecido a partir dos escritos de Alves (2005), Engels (1976) e Marx (2002).

Com o fito de responder à problemática de pesquisa, elegeu-se o delineamento histórico para recompor as relações sociais, o movimento de produção do conhecimento, bem como seus reflexos na educação ambiental escolar.

A Rede Municipal de Ensino (Reme) de Campo Grande compreende 195 unidades escolares. O universo desta pesquisa é representado por 86 escolas municipais de ensino fundamental localizadas na zona urbana da cidade de Campo Grande (figura 1), capital do estado de Mato Grosso do Sul.

Figura 1 - Mapa da cidade de Campo Grande e suas escolas municipais

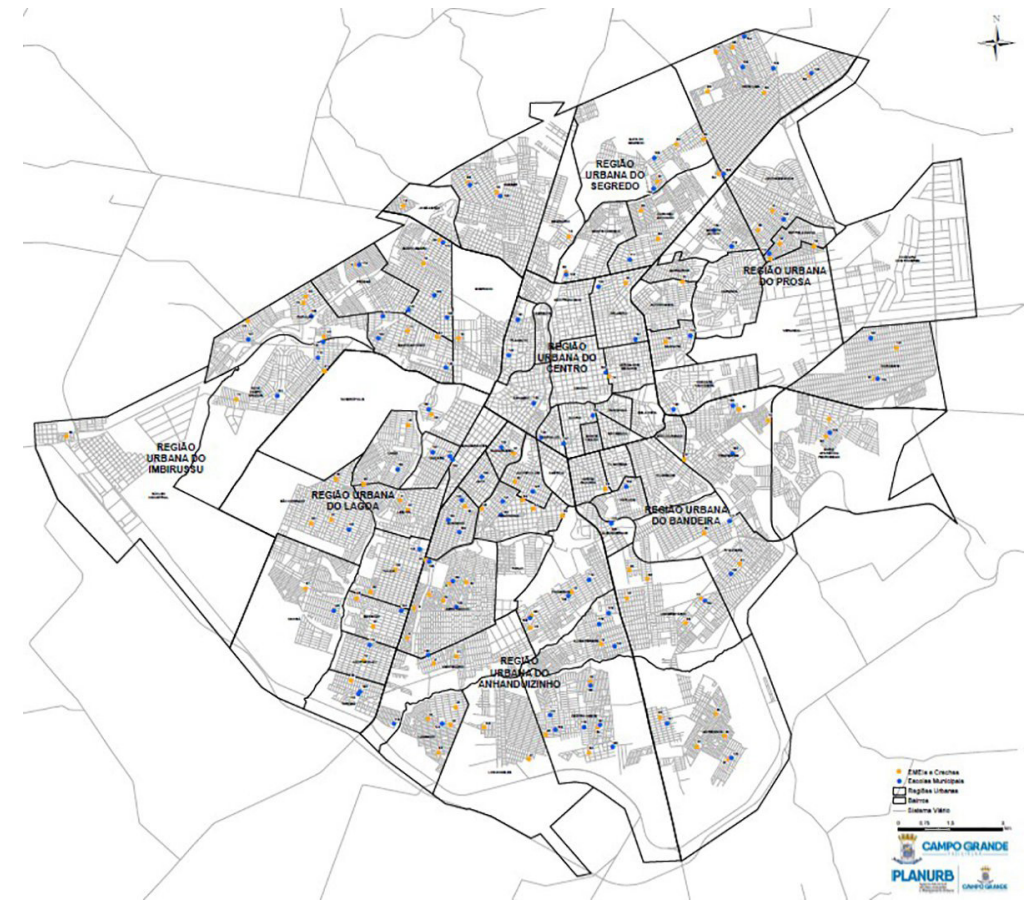

Fonte: https://cutt.ly/AmvLPHI. Acesso em: 13 jul. 2020.

O município de Campo Grande ${ }^{1}$ está localizado geograficamente na porção central de Mato Grosso do Sul, ocupando 2,26\% do território do estado. Tem área de $8.092,951 \mathrm{~km}^{2}$ (IBGE, 2011), dividida nas regiões de Anhanduizinho, Bandeira, Centro, Imbirussu, Lagoa, Prosa e Segredo, incluindo ainda os distritos de Anhanduí e Rochedinho. (UNIVERSIDADE FEDERAL DE MATO GROSSO DO SUL, 2016).

O levantamento dos dados empíricos ocorreu no período de agosto de 2019 a março de 2020. O procedimento de pesquisa consistiu em observações sistemáticas, em situação de trabalho, que incidiram sobre as reuniões bimestrais de formação continuada de professores promovidas pela Superintendência de Gestão das Políticas Educacionais, da Secretaria Municipal de Educação de Campo Grande (Semed). Acrescente-se ainda a análise dos manuais didáticos.

'A área do município é equivalente ao tamanho de alguns países como Porto Rico, Cabo Verde, Brunei, Luxemburgo, e um pouco maior que o Líbano e a Jamaica. 
Os manuais didáticos selecionados foram aqueles mais indicados pelas 86 escolas municipais de ensino fundamental da Reme nas áreas de Geografia e Ciências. Ambas são muito sensíveis à temática ambiental, daí a centralidade a elas atribuída.

Com fins de delimitação, foram considerados os dois títulos sobre os quais incidiram o maior número de escolhas em cada área. Os conteúdos de educação ambiental foram identificados a partir do documento Relatório das Escolas Participantes da Escolha de Livros² do ano de 2020, elaborado dentro do Programa Nacional do Livro Didático (PNLD). A escolha em referência foi finalizada pelas escolas no ano de 2019.

Para análise dos manuais didáticos adotou-se como referência teóricometodológica a ciência da história, pois, "[...] quase toda ideologia se reduz ou a uma concepção distorcida desta história, ou a uma abstração completa dela. A própria ideologia não é senão um dos aspectos desta história". (MARX; ENGELS, 1986, p. 24).

Estabelecida a priori, a categoria organização do trabalho didático (ALVES, 2005) utilizada para fins desse estudo, enfatiza três aspectos:

[...] a) ela é sempre uma relação educativa que coloca, frente a frente, uma forma histórica de educador, de um lado, e uma forma histórica de educando(s), de outro; b) realiza-se com a mediação de recursos didáticos, envolvendo os procedimentos técnico-pedagógicos do educador, as tecnologias educacionais pertinentes e os conteúdos programados para servir ao processo de transmissão do conhecimento; c) e implica um espaço físico com características peculiares, onde ocorre. (ALVES, 2005, p. 10-11).

Considerando a centralidade dos manuais didáticos no trabalho didático, a análise se pautou na identificação da abordagem apresentada com relação à educação ambiental, ou seja, se os conteúdos são abordados de modo a estimular o planejamento didático, a execução das atividades de ensino, e a cooperação entre professores de diferentes áreas.

As fontes secundárias foram buscadas em periódicos científicos e em livros referentes à educação ambiental, incluindo informações obtidas por meio de consultas a fontes digitais.

\section{Resultados e discussões}

Os resultados deste estudo se apoiaram no entendimento da educação ambiental a partir das relações sociais e das relações entre o homem e a natureza (REIGOTA, 2017).

No âmbito escolar, a educação ambiental tem sido preconizada como recurso para impor nova relação entre os professores, de modo a reforçar a abordagem interdisciplinar para além da centralidade no manual didático, e possibilitar a visão crítica do estudante.

Observações diretas nas reuniões bimestrais de formação continuada de professores, entre 2019 e 2020, revelaram que a temática ambiental tem sido abordada por meio dos componentes curriculares pertinentes às áreas de Ciências e de Geografia. Os professores dessas áreas são orientados a relacionar os objetos de conhecimento 
às suas implicações socioambientais, com base no documento Base Nacional Comum Curricular (BNCC) (BRASIL, 2017).

Temas da atualidade, em contínuo desenvolvimento, exigem uma permanente atualização; e fazê-lo junto com os alunos é uma excelente oportunidade para que eles vivenciem o desenvolvimento de procedimentos elementares de pesquisa e construam, na prática, formas de sistematização da informação, medidas, considerações quantitativas, apresentação e discussão de resultados etc. $O$ papel dos professores como orientadores desse processo é de fundamental importância. Essa vivência permite aos alunos perceber que a construção e a produção dos conhecimentos são contínuas e que, para entender as questões ambientais, há necessidade de atualização constante. (BRASIL, 1997, p. 188).

Embora o conhecimento das obras clássicas seja imprescindível à formação humana, sobretudo por possibilitar o acesso às respostas provisórias que foram sendo formuladas e projetadas pelos homens, nos diferentes momentos históricos se verificou que, para a maioria dos professores, os saberes para a educação ambiental se encontram no próprio manual didático dos alunos. Esse manual se valida enquanto instrumento de trabalho concebido por Comenius no século 17 de forma a "[...] resumir um programa de conteúdos informativos que, além de incorporar uma meta relativa ao grau de conhecimento a ser assimilado pelo aluno denotava, desde a origem, [...] o escasso conhecimento que exigia do professor" (ALVES, 2009, p. 155). Tal fato pode ser comprovado por meio dos portfólios elaborados pelos professores e discutidos durante as reuniões bimestrais.

Sendo tão centrais no trabalho didático, impôs-se a necessidade de analisar os manuais didáticos mais presentes na Reme. Quatro coleções referentes às áreas de Geografia e Ciências foram analisadas. Seguem-se as descrições desses instrumentos e as respectivas conclusões.

Título: Araribá mais: geografia

Obra coletiva concebida, desenvolvida e produzida pela Editora Moderna.

Autores: Cesar Brumini Dellore, Maira Fernandes, Daniel Zungolo Teixeira, Isabela Gorgatti Cruz, Eugênio Pacceli da Fonseca, Jonatas Mendonça dos Santos, Gustavo Nagib.

Editora: Moderna

Edição consultada: 1a., 2018.

O manual é composto por quatro volumes correspondentes aos anos finais do ensino fundamental $\left(6^{\circ}, 7^{\circ}, 8^{\circ}\right.$ e $9^{\circ}$ anos). Os conteúdos estão organizados em oito unidades, subdivididas em capítulos, compostos por textos gerais e seções complementares: mundo em escalas; integrar conhecimentos; lugar e cultura; ser no mundo; em prática; para refletir; e, atividades.

Conforme o conteúdo programático para o $6^{\circ}$ ano, a temática ambiental é apresentada em seções distribuídas ao longo de 18 capítulos. Os temas compreendem as transformações das paisagens, o impacto da intervenção do homem na natureza, a sustentabilidade das cidades, e os problemas ambientais no campo (DELLORE et al., 2018).

As seções que compõem os 19 capítulos do manual didático do $7^{\circ}$ ano contemplam o meio ambiente e sua sustentabilidade, a partir da regionalização do 
território brasileiro. Em 18 capítulos destinados ao $8^{\circ}$ ano, a questão ambiental é introduzida com base na regionalização do espaço geográfico mundial.

Dellore et al. (2018), ao conceberem o manual didático de geografia composto por 18 capítulos destinados ao $9^{\circ}$ ano, dedicam exclusivamente um capítulo à globalização e ao meio ambiente.

Observou-se que, em cada um dos volumes da coleção, a preocupação é a de que a educação ambiental seja abordada como tema contemporâneo, a partir de aspectos ligados à sustentabilidade. Outra intenção é a de resgatar a experiência do estudante, tendo como referência o espaço mais próximo (casa, bairro, cidade, etc.).

O manual do professor, para cada ano de ensino, reúne conteúdo impresso e material complementar. Envolve plano de desenvolvimento; sequência didática; proposta de acompanhamento da aprendizagem; e, material audiovisual digital. Assim, os autores pretendem responder à ideia de que tal instrumento precisa assegurar a possibilidade de potencializar o trabalho em sala de aula (BRASIL, 2020).

O manual estimula, ainda, a realização de projetos integradores e a produção de recursos, tais como livretos informativos, propostas de melhoria da qualidade de vida local, peças teatrais acerca da proteção ambiental.

Formalmente, o manual atende às unidades temáticas, aos objetos de conhecimento, às competências gerais e às habilidades preconizadas no documento intitulado Base Nacional Comum Curricular.

Entretanto, atualmente, as questões ambientais não podem ser apropriadamente tratadas, sem a consideração de duas questões angulares. A primeira, de natureza geral, reconhece que a ideia de sustentabilidade não é conciliável com a economia em uma sociedade "[...] na qual a produção é voltada não para o atendimento das necessidades humanas, mas, sim, para as necessidades de autorreprodução do capital" (MĖSZAROS, 2006, p. 43). Compromete o instrumento analisado, o fato de as relações sociais não terem sido sequer tocadas. A segunda questão angular tem como pressuposto a necessidade de abordagem interdisciplinar da educação ambiental. 0 manual didático em questão faz a abordagem disciplinar do conteúdo, submetendose aos ditames da especialização do saber. Ele não estimula o planejamento didático, a execução das atividades de ensino, e a cooperação entre professores de diferentes áreas.

\footnotetext{
Título: Teláris: geografia

Autor: José William Vesentini e Vania Rubia Farias Vlach

Editora: Ática

Edição consultada: 3a., 2018.
}

A coleção é composta por quatro volumes, tendo sido idealizada e elaborada para os anos finais do ensino fundamental, sem desconsiderar a realidade imediata dos alunos. (VESENTINI; VLACH, 2018).

Para cada ano do ensino fundamental, o manual didático do aluno está organizado em quatro unidades compostas por capítulos, subdivididos nas seguintes seções: geolink; glossário; texto e ação; conexões e atividades (BRASIL, 2020).

Composto ao todo por doze capítulos, o manual didático aborda a educação ambiental por meio de temáticas, tais como degradação do solo, impactos 
socioambientais da mineração, uso dos recursos hídricos, poluição atmosférica e aquecimento global, biodiversidade e transformações das paisagens.

Indústria e espaço geográfico, ocupação da terra pela agropecuária, solo urbano e enchentes, escassez de água potável, unidades de conservação, desmatamento e diversidades regionais são assuntos explorados no manual didático do $7^{\circ}$ ano.

De acordo com Vesentini e Vlach (2018), os manuais didáticos do $8^{\circ}$ e $9^{\circ}$ anos levam o aluno a refletir sobre a regionalização do mundo. A questão ambiental, na atualidade, é discutida a partir do conceito de globalização e da nova divisão internacional do trabalho.

O manual impresso do professor é constituído por duas partes. A primeira apresenta correspondência com o do manual didático do aluno, e a outra, referese às orientações específicas quanto aos procedimentos teórico-epistemológicos e metodológicos adotados. Já o instrumento digital, de caráter complementar, oferece subsídios para o planejamento e o desenvolvimento das aulas.

Assim como na coleção anterior, o manual recomenda o desenvolvimento de projetos que favoreçam a abordagem da educação ambiental enquanto tema transversal. O contrassenso é que esse discurso entra em contradição com a concepção disciplinar do trabalho didático proposto para educação ambiental. O estímulo aos projetos, por fim, é acompanhado da solicitação de produtos como cartazes, vídeos e exposições, dentre outros.

Domina o trabalho educativo a visão de educação ambiental escolar como recurso importante para a conservação da natureza. Ela geraria sensibilização e mudança de comportamento nos estudantes. Bastaria a conscientização dos homens. Mais uma vez, constata-se a desconsideração das relações sociais. O capital é omitido enquanto força determinante da desigualdade social e das agressões ao ambiente.

A educação ambiental escolar necessita ser pensada para além dos problemas ambientais imediatos. Necessita, também, ser entendida a partir de contribuições hauridas de áreas como a história, as ciências naturais, a geografia, as ciências ambientais e a cultura. Só esse caminho interdisciplinar pode viabilizar o tratamento transversal do ambiente.

\footnotetext{
Título: Araribá mais: ciências

Obra coletiva concebida, desenvolvida e produzida pela Editora Moderna.

Autores: Lais Alves Silva, Maira Rosa Carnevalle, Cristiane Grala Roldão, Daniel Hohl, Fernando Frochtengarten, Flavia Marques Ferrari, Juliana Bardi, Marta de Souza Rodrigues, Mauro Faro, Murilo Tissoni Antunes, Ruggero Tavares Santi, Tathyana Cristina Martins Cordeir Tumolo, Tassiana Fernanda Genzini de Carvalho, Vanessa Shimabukuro e Vivian Vieira.

Editora: Moderna

Edição consultada: 1a., 2018.
}

A coleção está pautada por duas intenções: o desenvolvimento do aluno e a valorização do trabalho do professor. Busca explorar situações nas quais os estudantes estejam em contato com fenômenos, e conjunturas em que as Ciências têm papel de destaque, além de procurar promover a reflexão sobre a natureza da área, suas particularidades, seus alcances e seus limites (SILVA et al., 2018).

A coleção é constituída por quatro volumes, sendo um manual didático específico para cada ano escolar. Todos os volumes estão divididos em oito unidades, as quais se subdividem em temas, atividades e seções, intituladas: explore; pensar ciência; 
atitude para a vida; e, compreender um texto. As atividades são distribuídas ao longo das unidades (BRASIL, 2020).

No manual didático de Ciências do $6^{\circ}$ ano, a temática ambiental é destacada na seção atitudes para a vida, ao término de cada unidade. Os assuntos explorados são turismo responsável, preservação do ambiente, resíduos eletrônicos, camada de ozônio, consumismo e lixo reciclável. São propostos, ainda, oficinas e projetos integradores com objetivo de fazer o aluno reconhecer seu protagonismo na mudança de comportamento relacionada ao ambiente.

O volume do $7^{\circ}$ ano propõe o estudo dos ecossistemas brasileiros, com o objetivo de estimular os alunos a caracterizá-los quanto às suas características físicas, relacioná-las à fauna e à flora, e avaliar os impactos de fenômenos naturais e antrópicos sobre o ambiente. (SILVA et al., 2018).

Os autores estimulam a realização de projetos que integrem o consumo consciente e o respeito à biodiversidade.

O consumidor consciente tem uma preocupação com todas as fases de produção e se interessa em saber a origem dos produtos. [...]. Além disso, escolhe empresas que se preocupam com a gestão de recursos naturais e são reconhecidas por práticas com responsabilidade socioambiental. Isso mostra que o consumidor consciente tem um grande poder. Ao escolher um produto e uma empresa, ele pode transformar sua compra em uma prática sustentável e ajudar na preservação da biodiversidade do planeta. (SILVA et al., 2018, p. 39).

De acordo com o excerto, a possibilidade de escolha sobre o que consumir parece óbvia. No entanto, é preciso considerar que grande parte de nossas escolhas estão condicionadas pelo mercado. O próprio conceito de consumo consciente pode ser um subterfúgio estratégico que cria oportunidades para alguns segmentos do capital.

Embora o fundamento da educação ambiental seja a relação entre o ser social e a natureza, de forma global, foi possível observar que os manuais didáticos do $8^{\circ}$ e $9^{\circ}$ anos enfatizam temáticas que se resumem à ação imediata do homem sobre o ambiente.

A discussão proposta no manual didático do $8^{\circ}$ ano acerca da educação ambiental parte do tema a energia que transforma o mundo. De acordo com os autores, o objetivo é

[...] estimular nos alunos uma reflexão sobre a importância do consumo consciente, do uso racional de energia e da utilização de alternativas viáveis para proporcionar maior economia às famílias, reduzir a pressão sobre os sistemas naturais e contribuir para minimizar os impactos negativos da ação humana sobre o meio ambiente e a sociedade. (SILVA et al., 2018, p. 46).

A partir do tema água virtual na produção agropecuária brasileira, o manual didático do $9^{\circ}$ ano desenvolve o conceito de Pegada Hídrica ${ }^{3}$ (WATER..., 2020). Objetiva estimular a conscientização do aluno sobre a água, recurso renovável indispensável à vida, porém limitado.

${ }^{3}$ Medida da apropriação da humanidade de água doce, em volumes de água consumida e/ou poluída. 
Com base no índice demográfico do país e na Pesquisa Nacional da Cesta Básica de Alimentos, realizada pelo Departamento Intersindical de Estatística e Estudos Socioeconômicos (DIEESE), o manual didático atenta para a necessidade de reflexão sobre o uso da água na produção de mercadorias consumidas diariamente, ou exportadas pelo país.

O manual impresso destinado ao professor observa correspondência com as unidades do manual didático do aluno, seus objetos do conhecimento, e seus procedimentos. O manual digital propõe projetos pedagógicos coletivos para estimular o engajamento dos estudantes na comunidade em que vivem. (BRASIL, 2020).

De acordo com a análise dos manuais didáticos da coleção, percebe-se que eles não explicitam o fato de que as relações atuais de destruição do ambiente e da vida têm como pano de fundo as relações de dominação e exploração próprias do capital. Portanto, a relação entre o homem e o ambiente não é pensada a partir de seus determinantes. Sem a consciência deles, torna-se impossível a construção de um projeto de transformação que crie um modo harmônico de vida entre os homens e o ambiente.

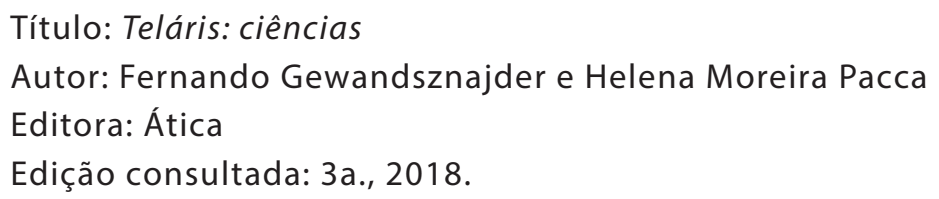

A coleção está organizada em quatro volumes. O manual didático de cada ano escolar está dividido em três unidades, contemplando as unidades temáticas presentes na BNCC. São elas: vida e evolução; matéria e energia; e Terra e universo. Essas unidades se subdividem em capítulos, que variam em número no interior de cada manual didático da coleção (BRASIL, 2020).

No primeiro volume, a educação ambiental é pensada a partir da concepção de que a ação do homem ocasiona alterações no ambiente. Em decorrência, a ênfase é atribuída às ações locais que visam a sustentabilidade. Nos 13 capítulos que o integram, a temática ambiental é tratada por meio dos subcapítulos recursos naturais renováveis e não renováveis, problemas na conservação do solo, tratamento de água e esgoto, resíduos sólidos e importância da biodiversidade.

Ecossistemas e impactos ambientais, tecnologia e ambiente, efeito estufa e poluição do ar são assuntos explorados e distribuídos ao longo dos dez capítulos que compõem o manual didático do $7^{\circ}$ ano.

De acordo com Gewandsznajder e Pacca (2018), os manuais didáticos do $8^{\circ}$ e $9^{\circ}$ anos precisam levar o aluno a refletir sobre o mundo atual e o papel do Brasil no seu conjunto. No volume do $8^{\circ}$ ano, que contém nove capítulos, a questão ambiental é tratada em capítulo específico, intitulado fontes de energia e impactos socioambientais.

Finalmente, no volume destinado ao $9^{\circ}$ ano, composto por 12 capítulos, os autores elaboraram um capítulo exclusivo para a educação ambiental. Ele aborda a importância da biodiversidade, das unidades de conservação, e dos objetivos do desenvolvimento sustentável.

O manual impresso do professor apresenta orientações didáticas complementares para que as atividades propostas no manual didático do aluno possam ser abordadas de forma criativa. Já o manual digital do professor estimula a 
realização de projetos integradores, e faz sugestões de sequências didáticas para a realização de aulas lúdicas e diferenciadas. (GEWANDSZNAJDER; PACCA, 2018).

A análise dos manuais didáticos de Ciências da coleção Teláris revelou que a questão socioambiental é discutida a partir da ênfase ao consumo individual consciente, como estratégia de enfrentamento à crise global.

O problema, contudo, não se encontra no plano do consumo, mas no âmbito da produção. Mèszáros (2007, p. 76) alerta para o fato de que "[...] o êxito do capital consiste apenas em postergar o momento em que se tornará uma necessidade inevitável enfrentar os graves problemas de seus sistemas, que até o momento continuam a se acumular".

A intensificação das formas de exploração humana e da natureza decorre das necessidades do capital, entendido como relação social. Abordar a temática ambiental na escola exige postura crítica e consciente de professores e de estudantes, sustentada na consciência dos determinantes dos graves problemas ambientais contemporâneos.

Mais uma vez, constatou-se a inobservância da interdisciplinaridade no tratamento das questões socioambientais. Nas escolas, continua predominando uma forma de organização do trabalho didático aferrada à organização técnica do trabalho de natureza manufatureira. A especialização do saber, como consequência da fragmentação dos conhecimentos disciplinares, ensejou uma visão compartimentada e imediatista da educação ambiental nas escolas da Reme.

A perpetuação desse tipo de relação educativa deve-se à centralidade do manual didático enquanto instrumento de trabalho (ALVES, 2005). Atribui-se a esse instrumento uma dupla função: orientar a metodologia a ser desenvolvida pelo professor, e assegurar a transmissão do conhecimento.

Nesse sentido, Lucchese e Alves (2013, p. 319) corroboram com o presente estudo:

[...] saliente-se, ainda que a importância do tema meio ambiente não pode ser apreendida por meio desse instrumento de trabalho especializado. Ele inviabiliza a abordagem interdisciplinar e reforça essa limitação por induzir uma metodologia que não rompe com a visão especializada do professor. [...] a educação ambiental nas escolas passa a acomodar-se à subdivisão de disciplinas curriculares [...] modo insuficiente para a compreensão dos fenômenos ambientais em sua totalidade. [...].

Durante a observação das reuniões bimestrais de formação continuada de professores promovidas pela Semed, foi possível verificar que, dentre os recursos adotados para o desenvolvimento dos conteúdos em educação ambiental, destacamse a confecção de maquetes, a elaboração de cartazes, a divulgação de campanhas educativas e a realização de gincanas culturais.

Constatou-se, também, que os professores de Ciências e de Geografia são orientados pela Semed a aderir a projetos de sensibilização, conscientização e sustentabilidade ambiental, em parceria com instituições públicas e privadas.

Foi o caso, por exemplo, do programa Reciclando nossas atitudes, desenvolvido pelo Departamento de Educação Ambiental da Solurb Soluções Ambientais ${ }^{4}$. Dentro dele foi elaborado o projeto Ações continuadas, que se destacou pela expressiva adesão

${ }^{4}$ Concessionária que gerencia a limpeza urbana e o manejo de resíduos sólidos em Campo Grande, MS, e que desenvolve programas de educação ambiental junto às escolas. 
das escolas municipais. O objetivo foi estimular os estudantes a realizar projetos sobre a temática ambiental por meio de gincanas voltadas à separação correta do lixo e à preservação do ambiente. A premiação ocorreu em dinheiro para as três primeiras escolas que mais pontuaram, sendo as demais agraciadas com placas de participação.

Importa considerar que, "[...] à primeira vista, parece um conjunto de práticas amigas do ambiente sob o ponto de vista de uma empresa consciente das suas potencialidades para a proteção do ambiente" (MASCARENHAS; COSTA, 2011, p. 161). Contudo, na prática, o foco muito específico da iniciativa limita a visão abrangente da questão ambiental. Por outro lado, a empresa em referência não é exemplo de lisura no que se refere ao tratamento do lixo em Campo Grande. Em diversos momentos, o questionamento à postura dela foi matéria de exploração pela mídia (BITENCOURT, 2020).

Outro exemplo foi a parceria entre a Semed e a Empresa Brasileira de Pesquisa Agropecuária (Embrapa), realizada durante a terceira edição da Expocampo. Com o título Agroecologia como perspectiva de sustentabilidade socioambiental na educação do campo, o objetivo do projeto foi valorizar a 'cultura' do homem do campo, seu modo de vida e as práticas de trabalho, por meio de exposição de produtos para comercialização.

Nessa seara, a discussão entra por um caminho tortuoso. Falar de "[...] uma forma cultural singular [...]" desligada do universal condena a discussão a pairar em um campo abstrato (ALVES, 2014, p. 54). De fato, a iniciativa não trata de 'cultura', nem de valorização do homem. O título da atividade não chega a disfarçar que a principal preocupação é a divulgação e a comercialização de produtos do campo.

Essas atividades acabam sendo tentativas esporádicas que só confirmam o essencial. A educação ambiental, de fato, é norteada, sobretudo pelo manual didático. Também no seu âmbito, conforme Alves (2008, p. 106), "[...] a transmissão do conhecimento na escola, [...], se identificou, de fato, com a difusão do conhecimento vulgar".

Ao pautar a prática educativa em conhecimentos fragmentados e atividades desconexas, os professores reforçam o tratamento dos conteúdos com base no senso comum, e se distanciam do rigor científico e do conhecimento culturalmente significativo. Dentro das salas de aula, os professores reiteram o uso dos "[...] instrumentos de trabalho de sempre, sobretudo o manual didático", expressão do conhecimento vulgar (ALVES, 2010, p. 57-58).

Faz-se urgente a recuperação do conhecimento, na escola, por meio do estudo dos clássicos. Estes, por captarem as contradições de seu tempo para responder às necessidades históricas do homem, contribuem para a formação de uma consciência crítica em direção à superação dos modismos da educação ambiental.

O estudo revelou que, na Reme de Campo Grande, a educação ambiental é decorrente de uma relação educativa, cujo domínio dos saberes escolares é condicionado ao instrumento de trabalho, por meio de uma abordagem conteudista e restrita aos componentes curriculares de Geografia e Ciências.

Essa educação ambiental compartimentada, desenvolvida sob a égide de uma organização técnica de trabalho de natureza manufatureira, inviabiliza a compreensão dos alunos acerca das contradições do ambiente e do capitalismo, impossibilitandoos de discutir as questões socioambientais a partir da realidade concreta. 


\section{Considerações finais}

Atualmente, a escola tem incorporado inúmeras funções sociais sob a promessa de educar o indivíduo em sua totalidade, a fim de dotá-lo de capacidade para intervir, sobretudo, nas questões sociais e ambientais em âmbito local.

Na prática, porém, um número expressivo de reuniões destinadas à formação continuada de professores ocorre de modo aligeirado, superficial, fragmentado e desconsiderando o processo histórico de construção do conhecimento. Isso vai ao encontro da ideologia dominante presente nos programas de governo, que têm como foco o reforço à reprodução do capital, não havendo espaço para a questão do conhecimento. Contribuem para a perpetuação de uma escola esvaziada de conhecimento significativo.

Se, na busca de saídas para a crise ambiental, é preciso previamente compreender como a relação homem-natureza se associa às relações sociais dominantes, o presente estudo apresentou evidências de que a educação ambiental escolar não tem dado contribuição nessa direção. Ela vem sendo dominada pelo senso comum. Mesmo em face da amplitude da questão ambiental e da proposta interdisciplinar da educação ambiental escolar, a centralidade da relação educativa e a abordagem disciplinar dos conteúdos tem sido exercida por pressão do instrumento de trabalho.

Esse instrumento, por excelência, tem sido o manual didático que, imbuído do caráter universal de ensinar tudo a todos, atende aos interesses do capital, e colabora ainda mais para a manutenção das desigualdades sociais. Em seu conteúdo está embutido o caráter disciplinar e fragmentário do conhecimento. No dia a dia da sala de aula, o conhecimento se reproduz em conformidade com os procedimentos técnicos também preconizados pelo manual didático. Por esse caminho, a educação assumiu um caráter livresco e verbalista. Afastou-se do rigor científico e das experiências vivas constituídas pelas relações entre o homem e o ambiente.

A escola, ao se valer de uma organização do trabalho didático regida pela especialização do saber e centrada no manual didático, inviabiliza, tanto para o professor quanto para o aluno, a possibilidade de "[...] acesso ao conhecimento culturalmente significativo haurido agora através de recursos como os meios de comunicação de massa e a Internet, bem como da recuperação de livros e outras modalidades de obras clássicas" (ALVES, 2008, p. 111).

Para tanto, torna-se imprescindível que o processo de formação continuada de professores proposto pelas redes de ensino esteja assentado na apreensão do percurso necessário para obtenção de respostas aos diversos questionamentos da ciência e da sua própria existência. Compete à escola, portanto, ao professor, planejar e desenvolver atividades pautadas no estudo de obras literárias. Isso permitirá que o aluno tenha acesso às respostas provisórias que foram sendo formuladas e projetadas pelos homens, nos diferentes momentos históricos.

Percebe-se, assim, que o retorno dos clássicos à escola contemporânea implica um fazer ímprobo, porém essencial na relação educativa. Emerge como recurso para reconstituição, no plano do pensamento, das demandas e contradições da sociedade. Subsidia o rompimento com o manual didático e recoloca a possibilidade de difusão do conhecimento dentro da escola. 
Por fim, infere-se que, a partir da superação da organização do trabalho didático de natureza manufatureira, e, por conseguinte, do manual didático, será possível suplantar essa escola anacrônica, orientada para a aquisição de informações prontas, e debelar as relações assimétricas entre os homens, e entre os homens e a natureza.

\section{Agradecimentos}

Agradecemos à Coordenação de Aperfeiçoamento de Pessoal de Nível Superior (CAPES) pela bolsa de doutorado concedida à primeira autora deste artigo.

\section{Referências}

ALVES, G. L. Arte, artesanato e desenvolvimento regional: temas sul-mato-grossenses. Campo Grande: Editora UFMS, 2014.

ALVES, G. L. Escola pública: funções, projeto de formação e trabalho didático. Educativa, Goiânia, v. 12, n. 1, p. 151-161, 2009. Disponível em: https://cutt.ly/HmbjhLj. Acesso em: 30 jun. 2021.

ALVES, G. L. Formação de professores: uma necessidade de nosso tempo? Revista HISTEDBR Online, Campinas, v. 8, n. 31, p. 102-112, 2008.

ALVES, G. L. História da educação: a produção teórica do trabalho didático. In: BRITO, S. H. A. (org.). A organização do trabalho didático na história da educação. Campinas: Autores Associados, 2010. p. 41-59.

ALVES, G. L. O trabalho didático na escola moderna: formas históricas. Campinas: Autores Associados, 2005.

BITENCOURT, E. Empresário pressiona TJ pelo fim de bloqueio de $\mathrm{R} \$ 101,5$ milhões por corrupção no lixo. O Jacaré, 25 maio 2020. Disponível em: https://cutt.ly/Rmhwban. Acesso em: 12 jun. 2020.

BRASIL. Lei n. 9394, de 20 de dezembro de 1996. Estabelece as diretrizes e bases da educação nacional. Brasília: Presidência da República, 1996. Disponível em: https://cutt.ly/EmbkiJA. Acesso em: 12 fev. 2020.

BRASIL. Lei n. 6.938, de 31 de agosto de 1981. Dispõe sobre a Política Nacional do Meio ambiente. Brasília: Presidência da República, 1981. Disponível em: https://cutt.ly/ambkaNI. Acesso em: 12 fev. 2020.

BRASIL. Lei n. 9.795, de 27 de abril de 1999. Dispõe sobre a educação ambiental, institui a Política Nacional de Educação Ambiental e dá outras providências. Brasília: Presidência da República, 1999. Disponível em: https://cutt.ly/5mbke2k. Acesso em: 12 fev. 2020.

BRASIL. Lei n. 13.005, de 25 de junho de 2014. Aprova o Plano Nacional de Educação 20142024 (PNE) e dá outras providências. Brasília: Presidência da República, 2014. Disponível em: https://cutt.ly/mmbj6FC. Acesso em: 12 fev. 2020.

BRASIL. Parecer CFE/CEGRAU n. 226, de 11 de março de 1987. Brasília: MEC, 1987. Disponível em: https://cutt.ly/jmg5ak8. Acesso em: 12 fev. 2020.

BRASIL. [Constituição (1988)]. Constituição da República Federativa do Brasil de 1988. Brasília: Presidência da República, [2016]. Disponível em: https://cutt.ly/ymbkvFh. Acesso em: 12 fev. 2020.

BRASIL. Ministério da Educação. Base nacional comum curricular: educação é a base. Brasília: MEC, 2017. 
BRASIL. Ministério da Educação. Diretrizes curriculares nacionais para a educação básica. Brasília: MEC, 2013.

BRASIL. Ministério da Educação. Guia de livros didáticos: PNLD 2020. Brasília: MEC, 2020. Disponível em: https://cutt.ly/qmbkF1y. Acesso em: 23 fev. 2020.

BRASIL. Ministério da Educação. Parâmetros curriculares nacionais: meio ambiente e saúde. Brasília: MEC, 1997. v. 9.

CARSON, R. Primavera silenciosa. São Paulo: Melhoramentos, 1962.

DELORS, J. Educação: um tesouro a descobrir. 2. ed. São Paulo: Cortez, 1999.

DELLORE, C. B.; FERNANDES, M.; TEIXEIRA, D. Z.; CRUZ, I. G.; FONSECA, E. P.; SANTOS, J. M.; NAGIB, G. Araribá mais: geografia. São Paulo: Moderna, 2018.

ENGELS, F. A dialética da natureza. Rio de Janeiro: Paz e Terra, 1976.

GEWANDSZNAJDER, F.; PACCA, H. M. Teláris: ciências. 3 ed. São Paulo: Ática, 2018.

IBGE. Censo demográfico 2010: características da população e dos domicílios: resultados do universo. Rio de Janeiro: IBGE, 2011. Disponível em: https://cutt.ly/9mblwzr. Acesso em: 23 abr. 2020.

LUCCHESE, N. R.; ALVES, G. L. A educação ambiental nas escolas estaduais de ensino médio em Campo Grande, MS. Revista HISTEDBR On-line, Campinas, v. 13, n. 51, p. 303-322, jun. 2013. Disponível em: https://cutt.ly/Emblpjs. Acesso em: 15 abr. 2020.

MARX, K. O capital: crítica da economia política. 19. ed. Rio de Janeiro: Civilização Brasileira, 2002.

MASCARENHAS, M. P. V.; COSTA. C. A. F. Responsabilidade social e ambiental das empresas: uma perspectiva sociológica. Revista Latitude, Maceió, v. 5, n. 2, p. 141-167, 2011. Disponível em: https://cutt.ly/amblziF. Acesso em: 17 abr. 2020.

MÈSZAROS, I. O desafio e o fardo do tempo histórico: o socialismo no século XXI. São Paulo: Boitempo, 2007.

MĖSZAROS, I. Desemprego e precarização: um grande desafio para a esquerda. In: ANTUNES, R. (org.). Riqueza e miséria do trabalho no Brasil. São Paulo: Boitempo, 2006. p. 27-44.

REIGOTA, M. O que é educação ambiental. São Paulo: Brasiliense, 2017.

SILVA, L. A. et al. Araribá mais: ciências: manual do professor. São Paulo: Moderna, 2018.

TALAMONI, A. C. B. et al. Histórico da educação ambiental e sua relevância à preservação dos manguezais brasileiros. In: PINHEIRO, M. A. A.; TALAMONI, A. C. B. (org.). Educação ambiental sobre manguezais. São Vicente: UNESP, 2018. p. 57-73.

UNIVERSIDADE FEDERAL DE MATO GROSSO DO SUL. Observatório de Arquitetura e Urbanismo. Estudo dos vazios urbanos na cidade de Campo Grande: as macrozonas e as zonas de uso do solo urbano. Campo Grande: UFMS, 2016. Disponível em: https://cutt.ly/YmvZJp5. Acesso em: 13 jul. 2020.

VESENTINI, J. W.; VLACH, V. R. F. Teláris: geografia manual do professor. 3. ed. São Paulo: Ática, 2018.

WATER footprint network: fair \& smart use of the world's fresh water. [2020]. Disponível em: https://waterfootprint.org/en/water-footprint/. Acesso em: 11 mar. 2020. 